\title{
Timber beam seismic design - A numerical simulation
}

\author{
Abdoullah Namdar, *Yun Dong, Yuyi Liu \\ Faculty of Architecture and Civil Engineering, Huaiyin Institute of Technology, China \\ ab_namdar@yahoo.com,badyun@163.com (*),liuyuyi88@163.com
}

\begin{abstract}
In order to design a seismic timber beam, the effect of near-fault ground motion on timber beam has numerically been investigated, with reference to small displacement theory. The simulated near-fault ground motion is applied on the fixed base of a timber frame model. The beam is placed in single span of a timber frame. The beam has two different length sizes of 1.8 and 3.3 meters. The seismic load-displacement, seismic load-strain and strain-displacement have been calculated for all models and shown in graphs. The beam is designed with nonlinear analysis method and some mechanical properties for all models have been used, in numerical analysis. The numerical analysis results indicate that, the inertial interaction, energy dissipation and nonlinear deformation of beams in timber frames have directly related with frame span. In beams with a smaller length, higher seismic loading caused lower displacement. The displacement is reduced by reducing the length of the beam. The inertial interaction, energy dissipation and nonlinear deformation are changed respect to the length of the beam. The innovation of this paper is to develop cycling graphs by using ABAQUS, to improve design of timber frame and give an adequate explanation of seismic behavior of timber beam.
\end{abstract}

KEYWORDS. Seismic load; Timber beam; Displacement; Nonlinear deformation; Cycling graphs.

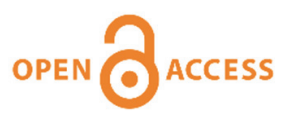

Citation: Namdar, A., Dong, Y., Liu, Y., Timber beam seismic design - A numerical simulation, Frattura ed Integrità Strutturale, 47 (2018) 451-458.

Received: 20.10 .2018

Accepted: 14.12.2018

Published: 01.01.2019

Copyright: (C) 2019 This is an open access article under the terms of the CC-BY 4.0, which permits unrestricted use, distribution, and reproduction in any medium, provided the original author and source are credited.

\section{INTRODUCTION}

$\mathrm{N}$ owadays, the timber well adapted in the construction industry, including timber frame which is very popular. The strength of timber depends on the material and manufacturing process. However, the timber seismic behavior is different from concrete and steel. There are several historical timber structures around the world available that need maintenance and retrofits. The Wentong pagoda timber tower with nine floors is one heritage and beautiful monument constructed in Huai'an city, Jiangsu province of China (Fig. 1). There are several towers made from timber frames existing in China, some of them are, Changzhou Tianning, Changzhou Wenbi Pagoda, Jimingsu-sunset, Lufeng Temple, Twin pagodas of Shuixi and etc. 
In the construction industry and related field, several characteristics of different structure, structural elements, substructure and construction materials are numerically, theoretically and experimentally reported in the literature [1-19], but little research has been done on timber structure design. A timber structure state of art has numerically been investigated, to understand seismic resistance by the evaluation of the load, displacement and stress have been applied on the timber structures [1]. An investigation has been made comparing the behavior of laterally loaded round and squared timber bolted joints [2]. A research work on damage of bamboo and wooden materials based on linear elastic fracture mechanics has been reported [3]. The collapse prediction and non-linear behavior of the T-joint have experimentally and numerically been investigated [4]. The measurement of the compression strength of wood was studied [5]. But seismic design of timber frame subjected to near-fault ground motions, developing cycling graph using ABAQUS, and an explanation of the seismic behavior of timber beams have never been reported in the literature. In this paper, the beam is placed in a single span of a timber frame, with two different length sizes of 1.8 and 3.3 meter. The timber frame is subjected to nearfault ground motions. The seismic load-displacement, seismic load-strain and strain-displacement curves have been investigated, to understand the inertial interaction, energy dissipation and nonlinear deformation of beams in timber frames, with reference to the small displacement theory.

\section{MATERIALS AND MODELING}

he failure mitigation of soil foundation and soil-footing interaction have been investigated, considering analytical and numerical analysis. 2D numerical analysis has been performed for soil-concrete foundation interaction by using ABAQUS software [20-21]. In the present study, 3D numerical analysis has been used to understand timber frame seismic response, during timber frame subjected to near-fault ground motion, also by using ABAQUS software. Fig. 1, shows Wentong pagoda timber tower with nine floors, the tower consists of small span timber frame. It is important to seismic analysis of timber frame, while many heritage and modern structure made up from timber. From other hand high flexibility of timber frame compare to steel and concrete frame, seismic resistance of timber frame shows more stability.

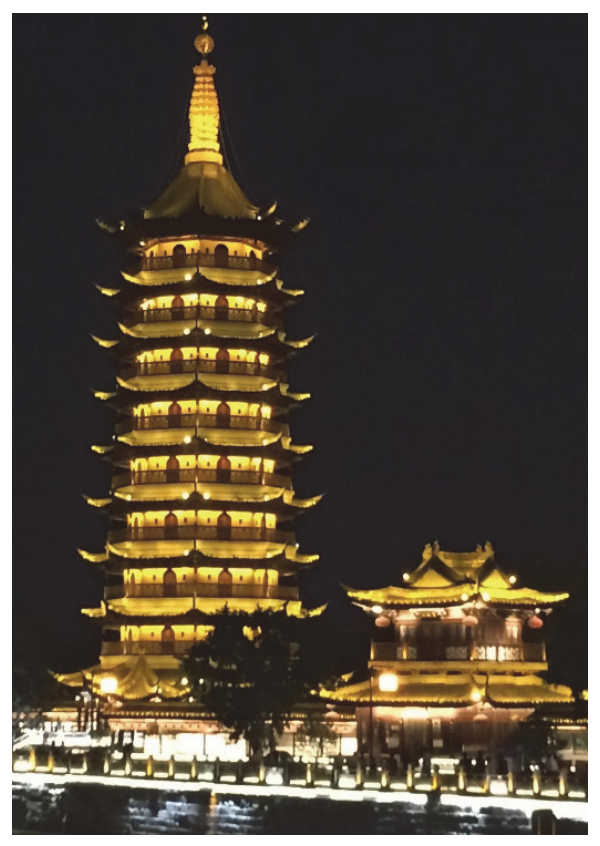

Figure 1: Wentong pagoda timber tower with nine floors is one heritage and beautiful monuments constructed in Huai'an city, Jiangsu province of China

Two timber frame models have been developed and analyzed, at each model the timber frame built up with single span. The size of spans in the first and second models are respectively 1.8 and 3.3 meter. In all models, the foundations of frame have been installed with suitable boundary condition. For each individual node, at the base of foundation, the fixed boundary condition has been simulated. It is hope this kind of boundary condition improves quality of analysis. The timber structure has been modeled with deformable mesh and has been numerically analyzed by using ABAQUS software. On the timber 
frame model, the near-fault ground motion is applied, and the three processes of loading-unloading mechanism have been shown, using cycling graph under ABAQUS environment. The method of merge node for all model including boundary condition, has been adopted in analysis of timber frame, during execute of numerical analysis. Both foundations of frame are characterized by the same geometry and material. Tab. 1, indicates the mechanical properties used in numerical analysis. The Figs. 2 and 3 show the timber frame and the type of meshes used in numerical analysis. Both frame and foundation are built up from the timber. The maximum value of seismic acceleration $\left(4.25\left[\mathrm{~m} / \mathrm{s}^{2}\right]\right)$ is applied on the model (Fig. 4). The beams are characterized by two different sizes ( 1.8 and 3.3 meter length), and both of beams have $0.3 \times 0.3$ meters cross section. The column size is 3 meter length, and $0.3 \times 0.3$ meters of cross section in both models. The timber frame is installed on a foundation of $0.3 \times 0.3 \times 0.3$ meter and beneath the foundation a footing is designed with dimension of $0.9 \times 0.9 \times 0.4$ meters.

\begin{tabular}{|c|c|c|c|}
\hline Type of material & $\begin{array}{l}\text { Modulus elasticity, } \\
\text { E (MPa) }\end{array}$ & Poisson's ratio, $\nu$ & $\begin{array}{l}\text { Unit weight, } \gamma \\
\left(\mathrm{kN} / \mathrm{m}^{3}\right)\end{array}$ \\
\hline Timber & 147.5 & 0.3 & 6.2 \\
\hline
\end{tabular}

Table 1: Soil and concrete mechanical properties [22].

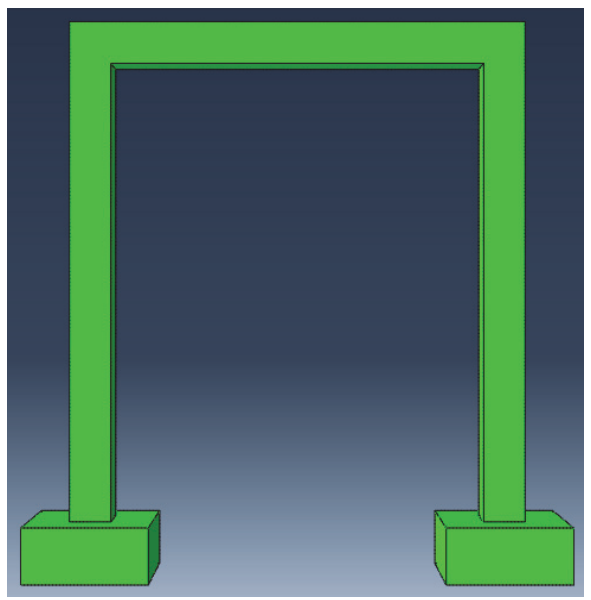

Figure 2: Typical timber frame models
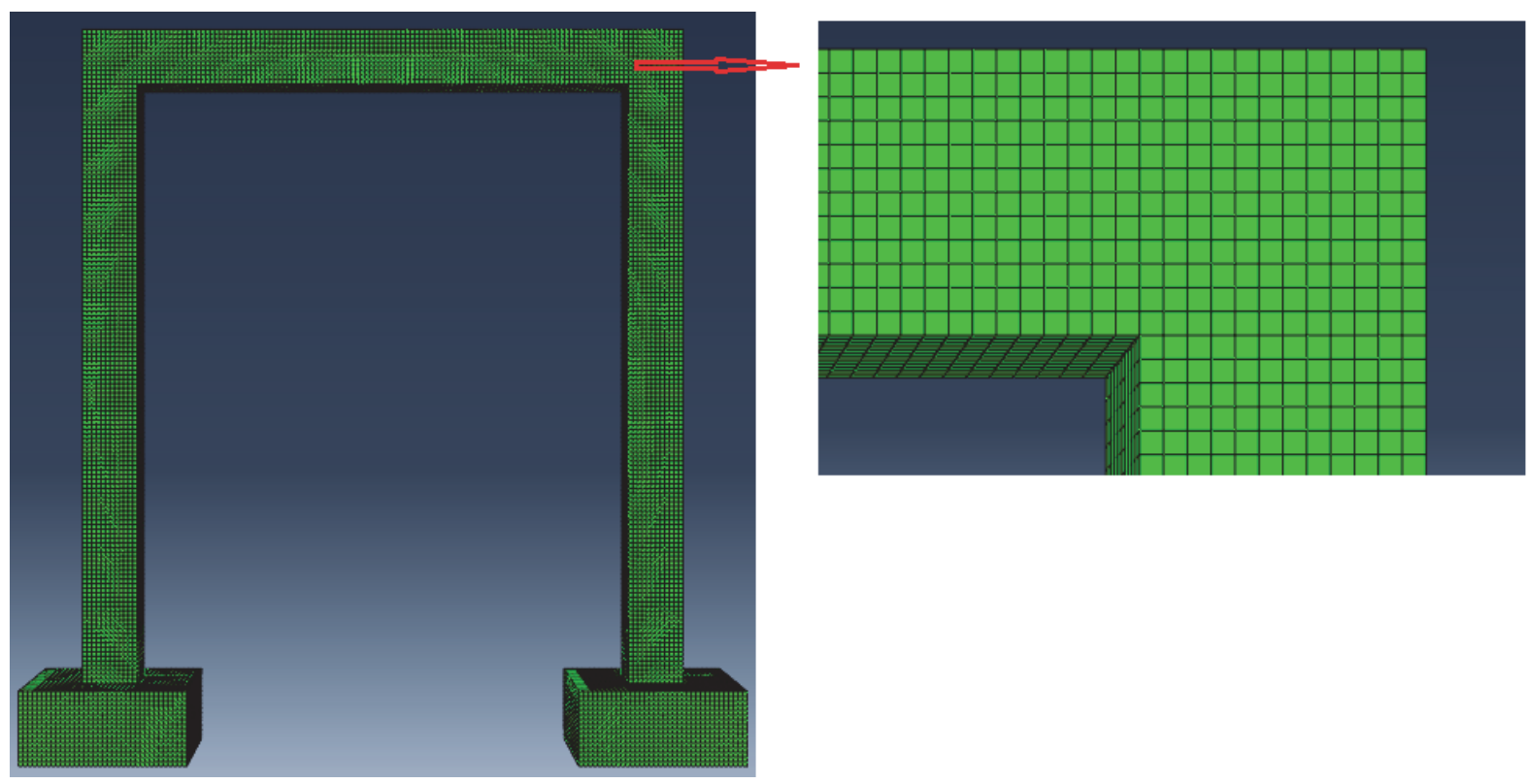

Figure 3: Typical timber frame models, with mesh is used in numerical simulation 


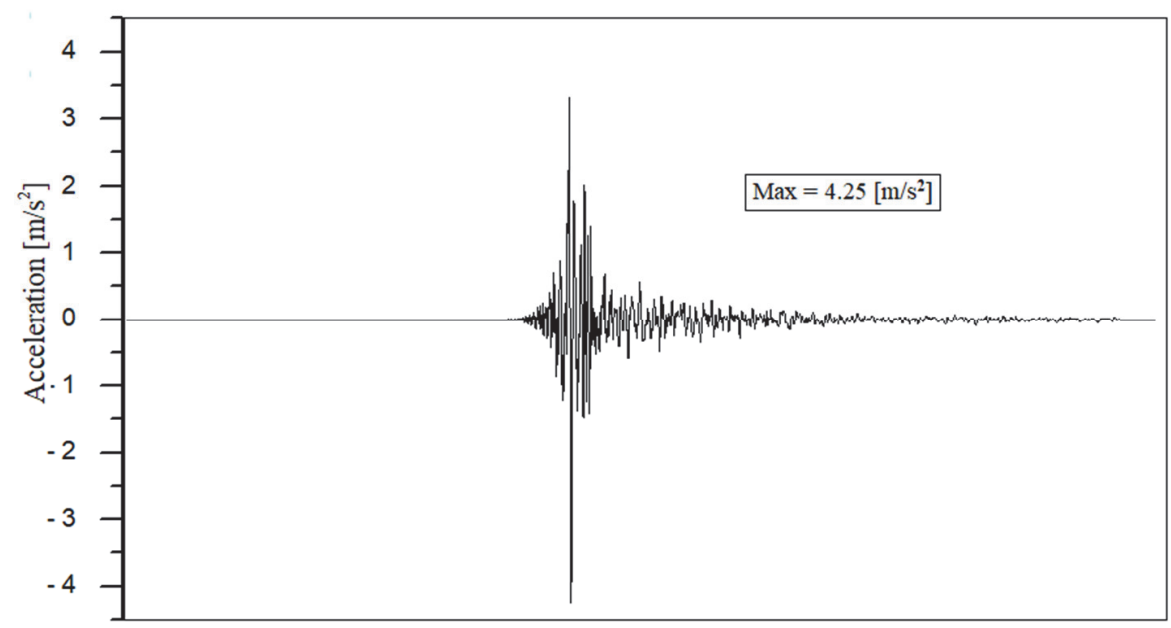

Figure 4: Acceleration history of earthquake used in numerical analysis [23].

\section{THEORETICAL CONCEPT}

timber beam of homogeneous, isotropic and linearly elastic material with modulus of elasticity E and Poisson A ratio $v$, and constant cross section is installed in single span of timber frame, has been numerically investigated. The model has been considered under internal and external dynamic loading.

Considering a static problem, during the action of internal and external forces. The sum of all the virtual work is:

$$
\delta^{\prime} W=0
$$

when all the external and internal forces are derived from a potential function $\mathrm{U}$, which is a function of the coordinates of the system of particles,

$$
\delta^{\prime} W=-\delta U
$$

The virtual work leads to establish the principle of stationary potential energy

$$
\delta U=0
$$

The above formulation may be extended to the dynamical problem of a system when it is subjected to time-dependent applied forces and geometrical constraints. The principal virtual work for the dynamical problem is given by:

$$
\delta \int_{t_{1}}^{t_{2}} T d t+\int_{t_{1}}^{t_{2}} \delta^{\prime} W d t=0
$$

where $\mathrm{T}$ is the kinetic energy of the system.

The state of the strain at a point of the body is defined by six components of strain $\left(\varepsilon_{x}, \varepsilon_{y}, \varepsilon_{z}, \gamma_{y z}, \gamma_{z x}, \gamma_{x y}\right)$. In small displacement theory, the strain-displacement relationship are given as follows [24]:

$$
\begin{aligned}
& \varepsilon_{x}=\frac{\partial u}{\partial x} \\
& \varepsilon_{y}=\frac{\partial v}{\partial y}
\end{aligned}
$$




$$
\begin{aligned}
& \varepsilon_{z}=\frac{\partial w}{\partial z} \\
& \gamma_{y z}=\frac{\partial w}{\partial y}+\frac{\partial v}{\partial z} \\
& \gamma_{z x}=\frac{\partial u}{\partial z}+\frac{\partial w}{\partial x} \\
& \gamma_{x y}=\frac{\partial v}{\partial x}+\frac{\partial u}{\partial y}
\end{aligned}
$$

In the present study, the above theoretical concept has been applied in numerical analysis, and the strain-displacement cyclic behavior of timber beam has been graphically shown, in order to understand timber beam seismic response.

\section{NUMERICAL ANALYSIS AND DISCUSSION}

he numerical analysis results show that the timber-frame resists well against seismic loading. In comparative analysis of two types of timber frames, the safety and the economy concepts are demonstrated. With higher span of timber frame, the bending moment on controls the beam seismic response, while in smaller span of timber frame the shear force is controlled seismic behavior of the beam. This phenomenon causes a nonlinear deformation of the beam. The same stiffness of timber cross section in both models, will induce larger displacements in beam with the longer length. Seismic response of both models illustrated that, for finite elastic strains, the timber beam involves large displacements and strains. Load-displacement in the cycling direction is obtained from numerical analysis, using ABAQUS software [Figs. 5-6]. In comparison models 1 and 2, the loading, unloading and reloading cycles, show different shape for each model. This is also reflected to displacement of beam. It is observed that increasing the distribution level of seismic load in timber beam, model 1 , shows a significantly effect on the change displacements mechanism.

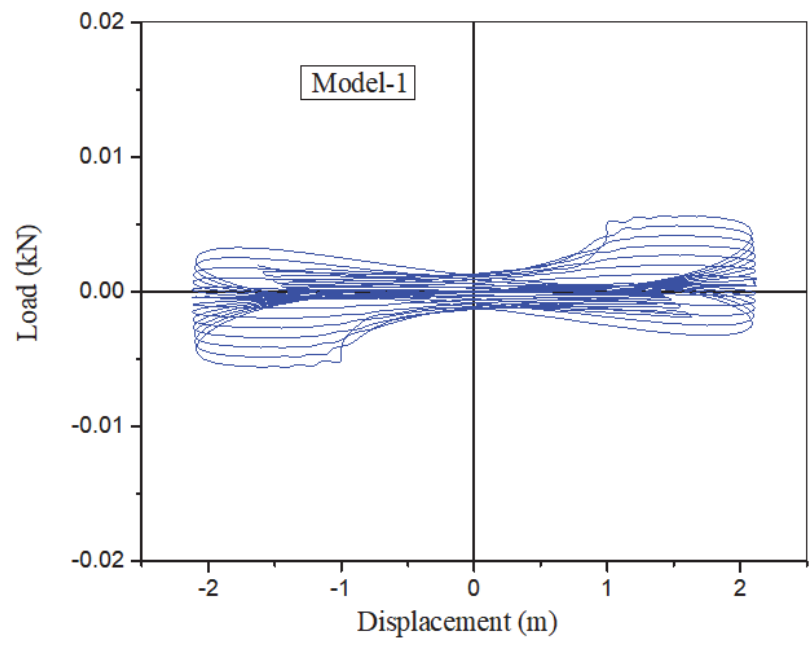

Figure 5: Load Vs displacement on timber beam with 3.3 (m) length, model-1.

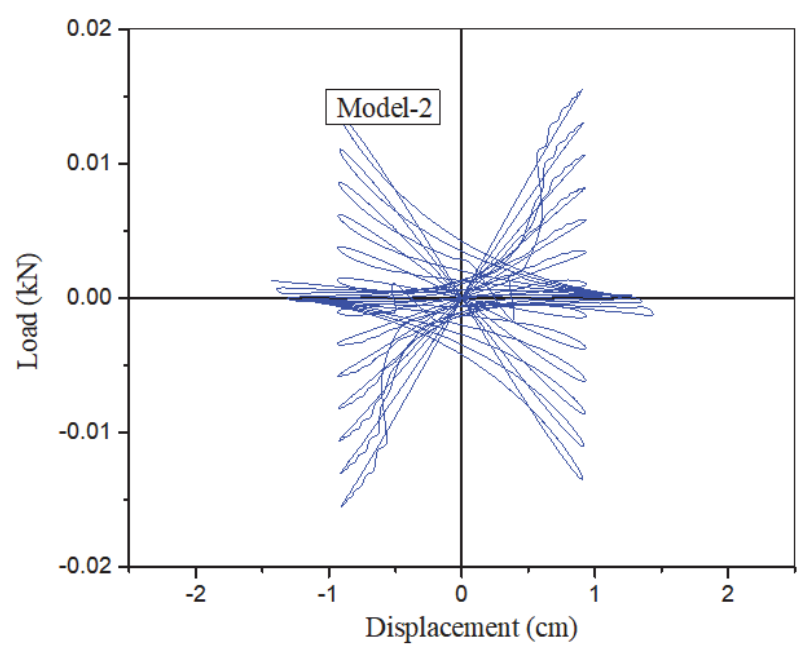

Figure 6: Load Vs displacement on timber beam with 1.8 (m) length, model-2.

The magnitude of a nonlinear deformation of timber beam during an individual earthquake, occurs both on the basis of the beam length and in the maximum displacement. Although there are significantly differences between developing cycling graphs of load-displacement in each models, which are produced on timber frame seismic load response. In 
consideration of models response, it has been observed that, the elastic displacement of timber beam with the same stiffness, but with nonlinear deformation, have been occurred. The inertia is developed in a timber frame during the seismic loading, producing shear, moment and torsional excitation. However, these loads cause hysteretic displacement variation in all timber frame components, with respect to flexibility level of timber frame. The seismic wave propagation into the timber frame, causes hysteretic displacement. The seismic energy dissipation significantly affects the overall timber frame seismic behavior. Considering the structural inertia, the kinematic interaction, results in stiff beam elements, which cause timber frame motions to deviate from free-field motion. The structure and foundation inertia, consist of the relative foundation-free field displacements. The flexural, axial and shearing nonlinear deformations of timber frame elements that occur, due to seismic load mechanism, are applied on model. These deformations significantly change the model behavior, especially in terms of damping, inertial interaction and energy dissipation.

The strain-displacement of timber frame is a representation of the nonlinear model behavior, and illustrates kinematic interaction of beam, which solve kinematic interaction problem beyond the ability of most commercial software. ABAQUS is able to show kinematic interaction, drawing cyclic graphs. The strain-displacement curve and nonlinear deformation of timber beam are dependent on the stiffness and geometry. The high strain-displacement have been observed in both models. The shape of strain-displacement curve are shown. The shear strain is developed with reduction of timber length [Figs. 7-8].

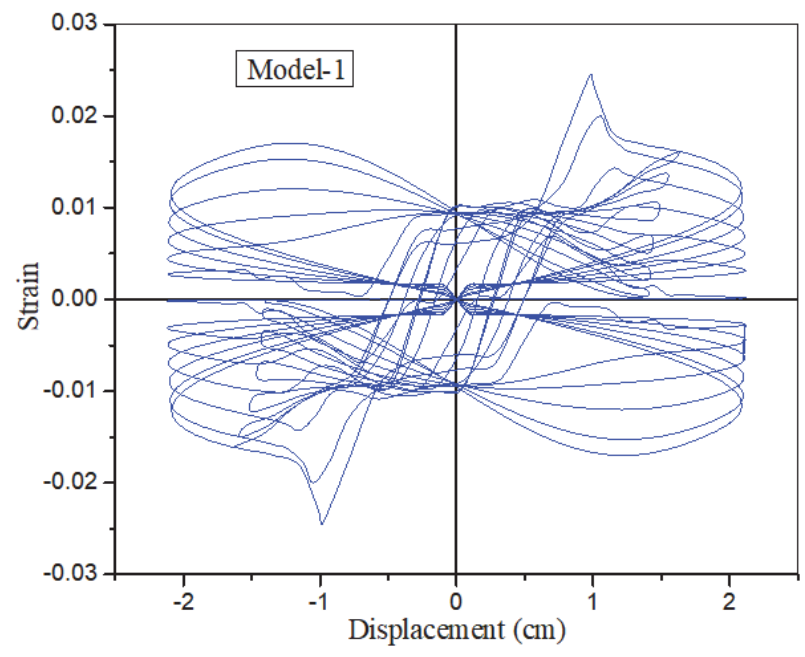

Figure 7: Strain Vs displacement on timber beam with 3.3 (m) length, model-1.

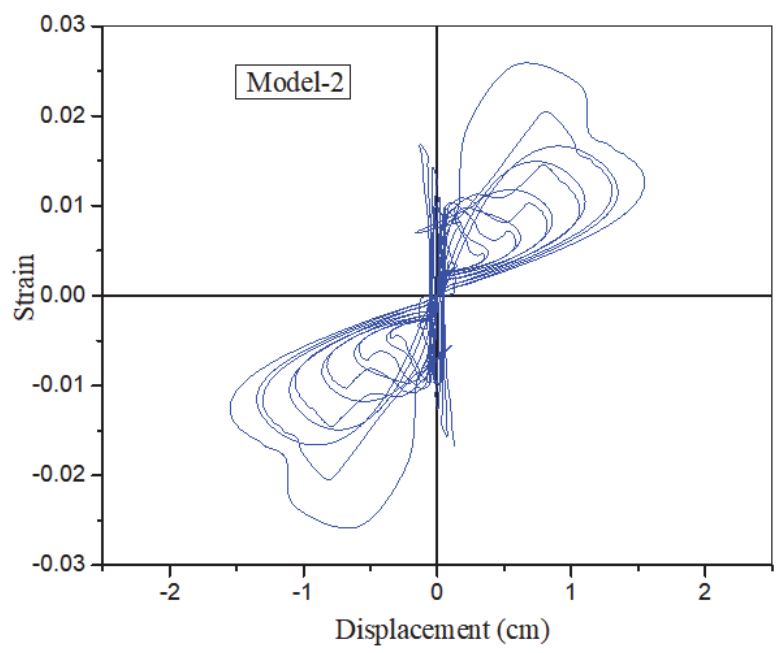

Figure 8: Strain Vs displacement on timber beam with 1.8 (m) length, model-2.

The load-strain curve describes the stiffness and damping characteristics of timber frame and beam-column interaction as well. Two different strain energies are developed in the models 1 and 2. The morphology of timber beams is correlated to different strain energy magnitude and shape for, each location and timber beams. From the seismic design point of view in a force-displacement diagram, the strain energy stored in the timber beam has been illustrated. The load-strain mechanism is part of the strain energy corresponding to the linear elastic response. For timber beam it is responding in the nonlinear range of loading, unloading and reloading. The energy dissipation causes nonlinear deformation and displacement. Therefore, the hysteresis loop of load-strain, illustrates the strain energy dissipation process. A flexibility of timber beam of $3.3(\mathrm{~m})$ reached at failure displacement with lower elastic strain energy, is reduced in this model by the damping ratio. The structural damping ratio will depend on elemental damping ratio and on the stiffness of the models. The relationship between the work done by seismic force and the elastic strain energy in one cycle of loading, unloading and reloading are shown in the graphs. The percentage of the seismic load carried out by beam and columns is affected to flexibility of frame. This process leads to develop different load-strain curve for each model. The magnitude and the direction of load sharing between beam and columns in each model, have specific characteristics, depending on timber frame span [Figs. 9-10].

In this numerical analysis, only one types of wood has been used in timber frame simulation. But it is indicated that [25], the strength of materials has significant effect on load sharing. The load sharing process effects to yielding of the lower strength and stiffness, resulting in change load transmission. 


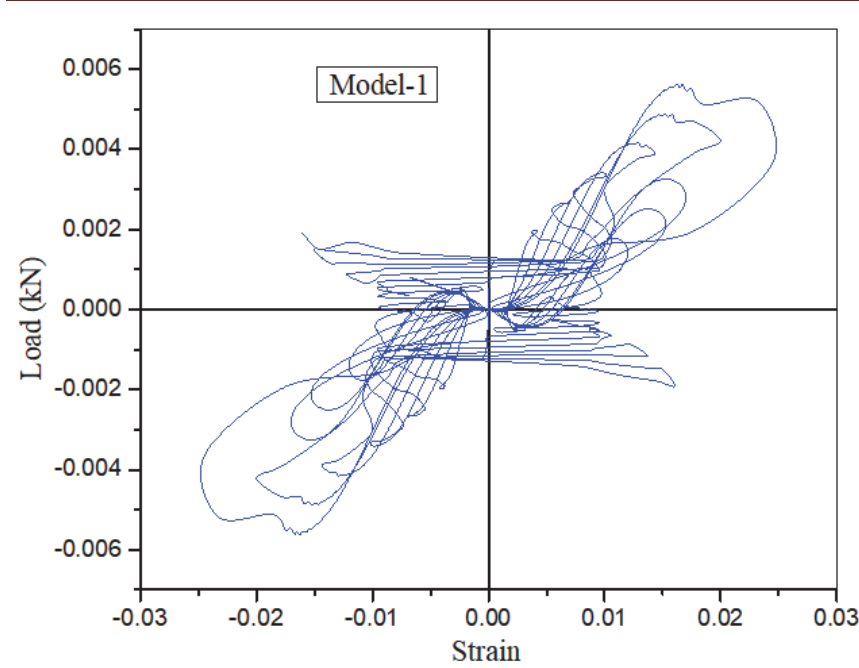

Figure 9: Load Vs strain on timber beam with 3.3 (m) length, model-1.

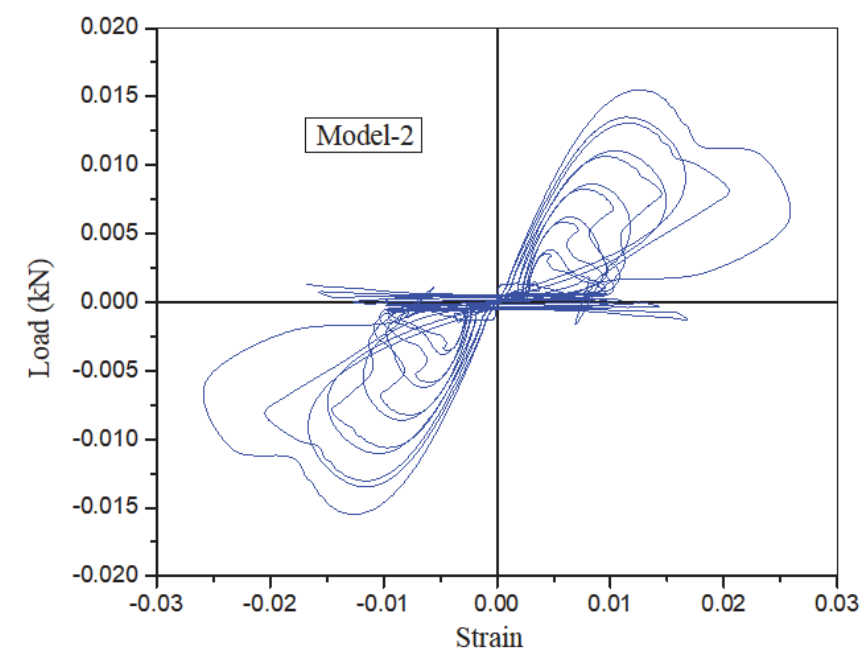

Figure 10: Load Vs strain on timber beam with 1.8 (m) length, model-2.

\section{CONCLUSION}

7 he timber beam seismic resistance correlated to displacement and nonlinear strain, has been investigated. The timber frame model performance is represented by seismic load-displacement, and by seismic load-strain. The load-displacement diagram relationship is subjected in considerable research in timber frame. The small displacement theory concept has been applied in numerical analysis, and the strain-displacement cyclic behavior of timber beam has been investigated, in order to understand the timber beam seismic response. In this work the follows goals have been achieved:

- From the load-displacement diagram analysis it has been found that, for the same stiffness in timber cross section in both models, it will induce larger displacements in beams characterized by longer length.

- The inertia is not negligible in a timber frame during subjected to seismic loading. It produces base shear, moment and torsional excitation which cause hysteretic displacement of timber beam.

- The deformation of beam significantly influences the model behavior, especially with respect to damping, inertial interaction and energy dissipation.

- The energy dissipation causes nonlinear deformation and the displacement. In load-strain mechanism, only the part of the strain energy, corresponding to the linear elastic response, is recovered.

- A flexible $3.3 \mathrm{~m}$ timber beam reaches the failure displacement with lower elastic strain energy.

- The percentage of the seismic load supported by beams and columns is affected by flexibility of frame.

\section{REFERENCES}

[1] Namdar, A., Darvishi, E., Feng, X. and Ge, Q. (2016). Seismic resistance of timber structure - a state of the art design. Procedia Structural Integrity, 2, pp. 2750-2756. DOI:10.1016/j.prostr.2016.06.343.

[2] Lokaj, A. and Klajmonová, K. (2017). Comparison of behaviour of laterally loaded round and squared timber bolted joints. Frattura ed Integrità Strutturale, 11 (39), pp. 2750-2756. DOI: 10.3221/IGF-ESIS.39.07.

[3] Haiyan, T. (2016). Damage of bamboo and wooden materials based on linear elastic fracture mechanics in garden design. Frattura ed Integrità Strutturale, 10(35), pp. 472-480. DOI: 10.3221/IGF-ESIS.35.53.

[4] Santos, C.L. dos., Morais, J.J.L and Jesus, A.M.P. de. (2015). Mechanical behaviour of wood T-joints. Experimental and numerical investigation. Frattura ed Integrità Strutturale, 9(31), pp. 23-37. DOI: 10.3221/IGF-ESIS.31.03.

[5] Jingran, G., Jian, L., Jian, Q and Menglin, G. (2014). Degradation assessment of waterlogged wood at Haimenkou site. Frattura ed Integrità Strutturale, 8(30), pp. 495-501. DOI: 10.3221/IGF-ESIS.30.60.

[6] Drbe, OF., El Naggar, MH. (2014). Axial monotonic and cyclic compression behaviour of hollow-bar micropiles. Can Geotech J, 52(4), pp. 426-41. DOI: 10.1139/cgj-2014-0052. 
[7] Namdar, A., Darvishi, E., Feng, X., Zakaria, I. and Yahaya, F.M. (2016). Effect of flexural crack on plain concrete beam failure mechanism - A numerical simulation. Frattura ed Integrità Strutturale, 10 (36), pp. 168-181. DOI: 10.3221/IGF-ESIS.36.17. DOI: 10.3221/IGF-ESIS.36.17.

[8] Namdar, A., Bin Zakaria, I., Bt Hazeli, A., Azimi, S. J., Bin Abd. Razak, A.S. and Gopalakrishna, G. S. (2013). An experimental study on flexural strength enhancement of concrete by means of small steel fibers. Frattura ed Integrità Strutturale, 7 (26), pp. 22-30. DOI: 10.3221/IGF-ESIS.26.03.

[9] Namdar, A. (2012). Natural minerals mixture for enhancing concrete compressive strength. Frattura ed Integrità Strutturale, 6 (22), pp. 26-30. DOI: 10.3221/IGF-ESIS.22.04.

[10] Namdar, A., Failure analysis of concrete frame - A numerical analysis. (2016). Procedia Structural Integrity 2, pp. 2796-2802. DOI: 10.1016/j.prostr.2016.06.350.

[11] Santis, A De., Bartolomeo, O Di., Iacoviello, D. and Iacoviello, F. (2008). Quantitative shape evaluation of graphite particles in ductile iron. Journal of Materials Processing Technology, 196 (1-3), pp. 292-302.

[12] Lazzarin, P., Livieri, P., Berto, F. and Zappalorto, M. (2008). Local strain energy density and fatigue strength of welded joints under uniaxial and multiaxial loading. Engineering fracture mechanics, 75 (7), pp. 1875-1889. DOI:10.1016/j.engfracmech.2006.10.019.

[13] Susmel, L. and Taylor, D. (2008). The theory of critical distances to predict static strength of notched brittle components subjected to mixed-mode loading. Engineering Fracture Mechanics, 75 (3-4), pp. 534-550. DOI:10.1016/j.engfracmech.2007.03.035.

[14] Bonora, N., Gentile, D., Pirondi, A. and Newaz, G. (2005). Ductile damage evolution under triaxial state of stress: theory and experiments. International Journal of Plasticity, 21 (5), pp. 981-1007. DOI: 10.1016/j.ijplas.2004.06.003.

[15] Rose, A., Taylor, R. and El Naggar, MH. (2013). Numerical modelling of perimeter pile groups in clay. Can Geotech J, 50(3), pp. 250-8. DOI: 10.1139/cgj-2012-0194.

[16] Iacoviello, F., Cocco, V Di., Cavallini, M., Marcu, T. and Molinari, A. (2005). Influence of sintered stainless steel microstructure on fatigue crack paths. Fatigue \& Fracture of Engineering Materials \& Structures, 28 (1-2), pp. 187193. DOI: $10.1111 /$ j.1460-2695.2005.00836.X.

[17] Salvini, P., Vivio, F. and Vullo, V. (2000). A spot weld finite element for structural modelling. International journal of fatigue, 22 (8), pp. 645-656. DOI: 10.1016/S0142-1123(00)00044-X.

[18] Abd Elaziz, AY. and El Naggar, MH. (2014). Geotechnical capacity of hollow-bar micropiles in cohesive soils. Can Geotech J, 51(10), pp. 1123-38. DOI: 10.1139/cgj-2013-0408.

[19] Cavallini, M., Bartolomeo, O Di. and Iacoviello, F. (2008). Fatigue crack propagation damaging micromechanisms in ductile cast irons. Engineering Fracture Mechanics, 75 (3-4), pp. 694-704. DOI: 10.1016/j.engfracmech.2007.02.002.

[20] Namdar, A. and Xiong, F. (2014). The understanding failure mitigation of soil foundation by using numerical analysis method. Frattura ed Integrità Strutturale, 8(30), pp. 138-144. DOI: 10.3221/IGF-ESIS.30.18.

[21] Namdar, A. (2016). A numerical investigation on soil-concrete foundation interaction. Procedia Structural Integrity 2, pp. 2803-2809. DOI: 10.1016/j.prostr.2016.06.351.

[22] Dackermann, U., Li, J., Rijal, R. and Crews, K. (2016). A dynamic-based method for the assessment of connection systems of timber composite structures. Construction and Building Materials, 2(102), pp. 999-1008. DOI: $10.1016 /$ j.conbuildmat.2015.10.009.

[23] https://strongmotioncenter.org/

[24] Washizu K., Variational Methods in Elasticity and Plasticity, 2nd ed, (1975). Published by PERGAMON PRESS.

[25] Alnuaim, AM., El Naggar, MH. and El Naggar, H. (2016). Numerical investigation of the performance of micropiled rafts in sand. Computers and Geotechnics, 77, pp. 91-105. DOI: 10.1016/j.compgeo.2016.04.002. 